\title{
Food and feeding habits of the red-belly tilapia (Tilapia zillii Gervais, 1848) (Pisces: Cichlidae) in Lake Ziway, Ethiopia
}

\author{
Elias Dadebo $^{1,}$, , Negesse Kebtineh ${ }^{2}$, Solomon Sorsa ${ }^{1}$, Kassaye Balkew ${ }^{1}$ \\ ${ }^{1}$ Department of Biology, Hawassa University, P. O. Box 5, Hawassa, Ethiopia \\ ${ }^{2}$ Department of Wild Life, Wetland and Fishery Management, Wondo Genet College of Forestry and Natural Resources, Hawassa \\ University, Shashemene, Ethiopia
}

\author{
Email address: \\ edadebo@yahoo.com(E. Dadebo), tamenege@gmail.com (N. Kebtineh), sorsasota@yahoo.com (S. Sorsa), \\ kassayebalkew@gmail.com (K. Balkew)
}

\section{To cite this article:}

Elias Dadebo, Negesse Kebtineh, Solomon Sorsa, Kassaye Balkew. Food and Feeding Habits of the Red-Belly Tilapia (Tilapia zillii Gervais, 1848) (Pisces: Cichlidae) in Lake Ziway, Ethiopia. Agriculture, Forestry and Fisheries. Vol. 3, No. 1, 2014, pp. 17-23. doi: 10.11648/j.aff.20140301.14

\begin{abstract}
Food and feeding habits of T. zillii were studied from 572 fish samples collected from April to May 2011 (dry season) and July to August 2011 (wet season) from Lake Ziway. Stomach content analysis was conducted using frequency of occurrence and volumetric methods of analyses. Macrophytes, detritus and phytoplankton were the dominant food categories occurring in $94.9 \%, 94.2 \%$ and $82.5 \%$ of the total stomachs examined and constituting $45.2 \%, 29.4 \%$ and $16.8 \%$ of the total volume, respectively. The contributions of insets, nematodes, zooplankton and ostracods were relatively low. Macrophytes (50.4\%), phytoplankton (21.8\%) and detritus (18.5\%) constituted the bulk of the food volume during the dry season. In the wet season detritus (40.8\%), macrophytes (37.8\%), phytoplankton (12.5\%) and insects (6.5\%) contributed the bulk of the food categories consumed. Phytoplankton, detritus and insects were important food categories of juveniles (5.0-9.9 $\mathrm{cm} \mathrm{TL}$ ) whereas macrophytes, detritus and phytoplankton were important food categories of adults. The importance of phytoplankton, detritus and insects declined with size of fish whereas the importance of macrophytes and nematodes increased with fish size. Based on the results of the stomach contents it was concluded that the species is an herbivorous feeding mainly on macrophytes, detritus and phytoplankton. The contribution of animal origin food was low.
\end{abstract}

Keywords: Diet composition, feeding, Lake Ziway, T. zillii

\section{Introduction}

The red-belly tilapia Tilapia zillii (Gervais, 1848) has wide spread distribution in tropical and sub-tropical regions of Africa and Eurasia $\left(35^{\circ} \mathrm{N}-10^{\circ} \mathrm{S}\right.$, equating to temperature range of $7-43^{\circ} \mathrm{C}$ ). In Africa, its distribution extends from Morocco and Egypt in the North, Côte d'Ivoire and Nigeria in the West to Democratic Republic of Congo in Central Africa [1]. It has been introduced in many countries including Ethiopia, Eritrea, Madagascar, Tanzania, Hawaii, Japan, Philippines, Singapore and United States of America [2]. It reaches a maximum length of $26.0 \mathrm{~cm}, 289 \mathrm{~g}$ weights and can live for about seven years [3]. It usually lives in water depth of up to $1 \mathrm{~m}$ [3].

T. zillii is economically and ecologically important as food fish, for aquaculture, commercial aquarium trade, weed control and recreational fishery in its native range and in many countries it has been introduced [4]. The species was introduced in Lake Ziway in 1980s with the intentions of increasing productivity of the lake [2].

Various authors have studied the food and feeding habits of T. zillii in the middle east and Africa, and reported that macrophytes, phytoplankton, insects (Chironomidae pupa and Chironomidae larvae), zooplankton and detritus constituted the major food categories of the species [2, 5-7]. According to Adeyemi et al. [8], the major food items of juveniles comprised of phytoplankton (green algae, blue green algae and diatoms), zooplankton, fish scales and bottom deposits. The same authors reported the importance of phytoplankton, zooplankton, benthic insects and fish scales for adult $T$. zillii in Gbedikere Lake, Nigeria. Negassa and Padanillay [7] and Mohamoud et al. [9] found aquatic macrophytes and vegetation matters of terrestrial 
origin as the most important food items of T. zillii in Lake Ziway, Ethiopia and in Lake Timsah, Egypt, respectively.

Few studies are available on the food and feeding habits of T. zillii in Lake Ziway. Negassa and Getahun [2] and Negassa and Padanillay [7] studied the feeding habits of the species and emphasized the importance of macrophytes, detritus and phytoplankton. Markos et al. [10] studied the feeding habits of T. zillii in Lake Ziway in connection with the mercury concentration and reported macrophytes, detritus and phytoplankton as important food categories.

According to Markos et al. [10], T. zillii is found at the lowest trophic level in Lake Ziway. Negassa and Padanillay [7] conducted comparative study on reproductive biology and feeding habits of $T$. zillii and $O$. niloticus in Lake Ziway. According to these authors, the dominant food categories of $T$. zillii are macrophytes, phytoplankton (green algae, blue green algae and diatoms), zooplankton, fish scales and bottom deposits. Since the information available on the food and feeding habits of T. zillii in Lake Ziway is scanty, detailed study is required to guide the management of the stock in the lake. The aim of this work was therefore, to study the food and feeding habits (diet composition, seasonal variation in diet and ontogenetic diet shifts) of the species in Lake Ziway.

\section{Materials and Methods}

\subsection{Description of the Study Area}

Lake Ziway (Latitude: $7^{\circ} 52^{\prime}-8^{\circ} 8^{\prime} \mathrm{N}$ and Longitude: $38^{\circ}$ $40^{\prime}-38^{\circ} 56^{\prime} \mathrm{E}$ ) is the most northerly lake of the four lakes in the Ziway- Shalla basin of the central part of the Ethiopian Rift Valley. Some evidences indicate that the four lakes, namely Lakes Langeno, Abijata, Shalla and Ziway formed one big lake when the water level was much higher than the present about 6,000 years ago [11]. The similarities of fossilized diatoms on the upper banks of the lakes and the present interconnections they have also suggest the possibility of being one lake in the past [11].

Lake Ziway is located about $145 \mathrm{~km}$ south of the capital city, Addis Ababa at an altitude of 1,636 m, with a surface area of $434 \mathrm{~km}^{2}$ [11]. The maximum depth of the Lake is $7 \mathrm{~m}$, mean depth is $2.5 \mathrm{~m}$ and the shoreline length is $137 \mathrm{~km}$ [12]. Two major inflows namely Rivers Meki and Katar enter the lake from the north western and southeastern plateaus, respectively. The lake has an outflow, Bulbula River, which is the major source of freshwater to otherwise highly saline Lake Abijata (Figure 1). The lake water is suitable for irrigation purpose and as a result, much of the land around it is under continuous cultivation for vegetables, fruits production and commercial floriculture. The climate of Lake Ziway region is semi-arid to sub-humid with mean temperature and precipitation of $25^{\circ} \mathrm{C}$ and $650 \mathrm{~mm}$ per year, respectively [13].

Because of the shallowness of the lake the littoral zone extends several hundreds of meters into the lake and

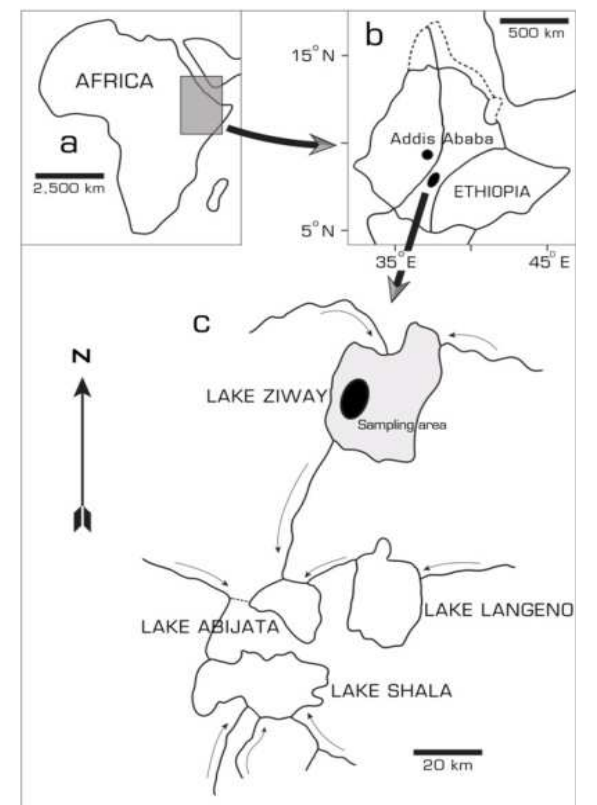

Figure 1. Map of Africa with horn of Africa region highlighted (a), map of Ethiopia with the southern rift valley lakes area indicated (b) and map of the Ziway-Shala basin lakes (with the sampling area in Lake Ziway indicated (c)

fringed by thick stands of emergent, submergent and floating vegetation (Cyperus, Papyrus, Phragmites mauritianus, Typha domingensis, Eicchorina crassipes, Hydrilla verticulata and Alisma plantogo [14]. The phytoplankton community is dominated by blue green algae (Microcystis, Lyngbya, Coelospharium, Merismopedia, Chroococcus, Anabaena), diatoms (Naviculla, Cymbella, Surirella, Gyrosigma, Nitzschia, Synedra, Pinnularia) and green algae (Scenedesmus, Spirogyra, Pediastrum, Ankistrodesmus, Cosmarium and Botryococcus) [7].

The zooplankton community of the lake is composed of cyclopoid copepods (Thermocyclops, Mesocyclops), cladocerans (Moina, Diaphanosoma, Cerriodaphnia, and Bosmina) and rotifers (Brachionus and Keratella). The bottom fauna comprises gastropods (Anisus natalensis, Biomphalaria sudanica, Bullinus forskahlii, Lymnea natalensis and Mellanoides tuberculata), different kinds of insects, spiders, ostracods, and nematodes [7].

The indigenous fish fauna of the lake include: The Nile tilapia (Oreochromis niloticus), the African big barb (Labeobarbus intermedius), the straightfin barb (Barbus paludinosus), the stone lapping (Garra quadrimaculata) and the black lampeye (Aplocheilichthys antinorii). The barbus species could be more diverse than mentioned above. The crucian carp (Carassius carassius) and T. zillii are exotic species introduced into the lake several decades ago with the aim of boosting the productivity of the lake [15]. The African catfish (Clarias gariepinus) was introduced accidentally as live fish were being transported from Lake Langeno to the cold storage site at the vicinity of Lake Ziway [15]. 


\subsection{Sampling and Measurements}

Fish samples were collected using experimental monofilament gillnets $(40 \mathrm{~mm}, 50 \mathrm{~mm}, 60 \mathrm{~mm}$ and $80 \mathrm{~mm}$ stretched mesh size). In addition, fish were purchased from the commercial landings of the fishermen. In order to obtain juvenile fish a $6 \mathrm{~mm}$ mesh beach seine was used in the shallower part of the lake. Samples were collected in April and May (dry season) and July and August (wet season) in the year of 2011. Total length (TL) was measured to nearest millimeter and the total weight (TW) of each fish was weighed to the nearest gram using a digital balance (Scaltec Model 23565, USA).

\subsection{Diet Composition}

The stomach content of each fish was kept in separate sampling bottles containing 5\% formalin solution. The stomach contents were then examined using a compound microscope (Leica, DME, magnification 100x). The relative importance of the different food items found in the stomach contents were determined using frequency of occurrence and volumetric methods [16]

In frequency of occurrence method, the number of stomach samples in which a given food item was found was expressed as a percentage of all non-empty stomachs examined. This method gives an estimate of the proportion of the population that feeds on a particular food item. This method is advantageous to establish relative abundances and requires less time and apparatus. It is however inadequate when a significant component of the diet does not occur in discreet units of uniform size. It provides little information on the food values of different items. In volumetric analysis, food items were sorted into different taxonomic categories, and the water displaced by a group of items in each category was measured in a partially filled graduated cylinder [16]. The volume of water displaced by each category of food items was expressed as a percentage of the total volume of the stomach contents [16].

In quantifying the volume of microscopic food items, the stomach content from each sample was diluted with tap water to a known volume. After thoroughly mixing the samples, one drop was taken on a microscope slide. The numbers of different food items were counted from 3 field of visions at different parts of the cover slip, and the total number of each food item per stomach sample was calculated by multiplying the mean number of each food items in a field of vision by the total number of field of vision under a cover slip area, and by total number of drops in the diluted stomach sample. The relative volume of each food item in a stomach was computed by multiplying the proportion of each food item in a drop by the total volume of the stomach content. Mean volume percentage of food items was calculated using the method of Wallace [17]

\subsection{Statistical Analysis}

A chi-square $\left(\chi^{2}\right)$ test was employed to compare the variations of the frequency of occurrence of the different food categories during the dry and wet seasons [19]. Similarly, the volumes of the different food categories were compared using Mann-Whitney's U test during the dry and wet seasons [18]. This non-parametric test was used because the data did not satisfy the assumption of equal variance to employ parametric test.

Dietary overlap between different length-classes was calculated using Schoener Diet Overlap Index (SDOI) [19], using the following formula:

$$
\alpha=1-0.5\left(\sum_{i=1}^{n}|p x i-p y i|\right)
$$

where $\alpha$ is percentage overlap, SDOI, between length classes $x$ and $y$, pxi and pyi are proportions of food category (type) $i$ used by length classes $x$ and $y$, and $n$ is the total number of food categories. Overlap in the index is generally considered to be biologically significant when the value $\alpha$ exceeds 0.60 [20].

\section{Results}

\subsection{Diet Composition}

Out of the total number of 612 fish samples collected, $572(93.5 \%)$ had some food in their stomachs whereas the remaining $40(6.5 \%)$ were empty. The size range of fish used for stomach content analysis was $5.4-24.0 \mathrm{~cm}$ TL and 3.2-266.6 g TW. T. zillii in Lake Ziway consumed different food categories including macrophytes, detritus, phytoplankton, insects, nematodes, ostracods and zooplankton. Food of plant origin, namely, macrophytes, detritus and phytoplankton constituted the bulk of the food of T. zillii in Lake Ziway occurring in 94.9\%, 94.2\% and $82.5 \%$ of the stomachs and comprising $45.2 \%, 29.4 \%$ and $16.8 \%$ of the total volume, respectively (Table 1 ).

Food of animal origin comprised insects (Diptera, Ephemeroptera, Plecoptera and Hemiptera), nematodes, zooplankton (Copepoda and Cladocera) and ostracods. The importance of these food categories was relatively low in the diet. Among food of animal origin, insects were relatively important occurring in $38.3 \%$ of the stomachs and comprising $6.0 \%$ of the total volume (Table 1). Other animals were of little importance.

\subsection{Seasonal Variation in the Diet}

The frequency of occurrence of macrophytes and phytoplankton significantly varied during the dry $(n=272)$ and wet $(n=300)$ seasons $\left(\chi^{2}\right.$ test, $\left.P<0.01\right)$. Similarly the volumetric contributions of mcarophytes, phytoplankton and detritus significantly differed during the two seasons of the year ( $\mathrm{U}$ test, $\mathrm{P}<0.01$ ). Macrophytes were the most important food items during the dry season, occurring in $51.4 \%$ of the stomachs and constituting $50.4 \%$ of the total volume of the food categories (Table 2). During the wet season, their contribution declined slightly occurring in $43.5 \%$ and comprising $37.8 \%$ of the total volume (Table 2 ).

The contribution of phytoplankton was higher during the dry season than the wet season (Table 2). They occurred in 
$85.7 \%$ and $74.9 \%$ of the stomachs during the dry and wet seasons and their volumetric contribution was $21.8 \%$ and $12.5 \%$, respectively (Table 2). Diatoms and blue green algae were of comparable importance during both dry and wet seasons (Table 2). The frequency of occurrence of detritus was comparable during the dry (47.7\%) and wet $(46.5 \%)$ seasons but its volumetric contribution was higher during the wet season $(40.8 \%)$ than the dry season $(18.5 \%)$ (Table 2).

Insects and nematodes occurred in relatively fewer number of stomachs and their volumetric contribution was low (Table 2). The contribution of insects was more or less comparable during both seasons. During the dry season, insects occurred in $22.4 \%$ of the stomachs and constituted $5.7 \%$ of the total volume of food items (Table 2). During the wet season, insects occurred in $15.9 \%$ of the stomachs and accounted for $6.5 \%$ of the total volume of food items (Table 2).

Nematodes occurred in $7.3 \%$ and $9.7 \%$ of the stomachs during the dry and wet months, respectively. Their volumetric contribution was $2.2 \%$ and $1.8 \%$ of the total volume of food items during the dry and wet seasons, respectively (Table 2). Ostracods and zooplankton were of little importance during both dry and wet periods, because they occurred in only few stomachs and their volumetric contribution was insignificant (Table 2).

Table 1: Frequency of occurrence (\%) and volumetric contribution (\%) of various food items in the diet of T. zillii sampled from Lake Ziway (n=572). Note that the sum of the food categories in bold adds up to $100 \%$ in volumetric analysis.

\begin{tabular}{ccccc}
\hline \multirow{2}{*}{ Food item } & \multicolumn{2}{c}{ Frequency of occurrence } & \multicolumn{2}{c}{ Volumetric contribution } \\
& Frequency & Percent & Volume (ml) & Percent \\
\hline Macrophytes & $\mathbf{5 4 3}$ & $\mathbf{9 4 . 9}$ & $\mathbf{9 4 . 3}$ & $\mathbf{4 5 . 4}$ \\
Detritus & $\mathbf{5 3 9}$ & $\mathbf{9 4 . 2}$ & $\mathbf{6 1 . 4}$ & $\mathbf{2 9 . 6}$ \\
Phytoplankton & $\mathbf{4 7 2}$ & $\mathbf{8 2 . 5}$ & $\mathbf{3 5 . 3}$ & 11.1 \\
Diatoms & 449 & 78.5 & 23.1 & 3.9 \\
Blue green algae & 367 & 64.2 & 8.2 & 1.6 \\
Green algae & 213 & 37.2 & 3.3 & 0.3 \\
Euglenoids & 49 & 8.6 & 0.6 & $\mathbf{6 . 1}$ \\
Insects & $\mathbf{2 1 9}$ & $\mathbf{3 8 . 3}$ & $\mathbf{1 2 . 6}$ & 4.7 \\
Diptera & 200 & 35 & 9.8 & 0.9 \\
Ephemeroptera & 39 & 6.8 & 1.8 & 0.24 \\
Plecoptera & 18 & 3.1 & 0.5 & 0.2 \\
Hemiptera & 9 & 1.6 & $\mathbf{3 . 5}$ & $\mathbf{1 . 5}$ \\
Nematodes & $\mathbf{9 8}$ & $\mathbf{1 7 . 1}$ & $\mathbf{0 . 6}$ & $\mathbf{0 . 2 9}$ \\
Ostracods & $\mathbf{4 4}$ & $\mathbf{7 . 7}$ & $\mathbf{0 . 3}$ & 0.1 \\
Zooplankton & $\mathbf{1 2}$ & $\mathbf{2 . 1}$ & 0.3 & 0.14 \\
Copepods & 12 & 2.1 & 0.004 & 0.002 \\
Cladocerans & 2 & 0.35 & & \\
\hline
\end{tabular}

Table 2: Relative contribution (\%) of different food items in the diet of T. zillii during dry ( $n=272)$ and wet $(n=300)$ season from Lake Ziway. Note that the sum of the major categories of food items in bold adds up to $100 \%$ in volumetric analysis.

\begin{tabular}{|c|c|c|c|c|}
\hline \multirow{2}{*}{ Food item } & \multicolumn{2}{|c|}{ Frequency of occurrence ( $\%)$} & \multicolumn{2}{|c|}{ Volumetric contribution (\%) } \\
\hline & Dry season & Wet season & Dry season & Wet season \\
\hline Macrophytes & 51.4 & 43.5 & 50.4 & 37.8 \\
\hline Detritus & 47.7 & 46.5 & 18.5 & 40.8 \\
\hline Phytoplankton & 85.7 & 74.9 & 21.8 & 12.5 \\
\hline Diatoms & 43.2 & 35.3 & 15.2 & 7.7 \\
\hline Blue green algae & 37.1 & 27.1 & 4.7 & 2.9 \\
\hline Green algae & 21.7 & 15.6 & 1.7 & 1.5 \\
\hline Euglenoids & 2.3 & 6.3 & 0.2 & 0.4 \\
\hline Insects & 32.4 & 15.9 & 5.7 & 6.5 \\
\hline Diptera & 30.6 & 15.8 & 4.1 & 5.3 \\
\hline Ephemeroptera & 2.9 & 3.9 & 0.9 & 0.9 \\
\hline Plecoptera & 2.1 & 1.0 & 0.5 & 0.2 \\
\hline Hemiptera & 0.0 & 1.5 & 0.2 & 0.1 \\
\hline Nematodes & 7.3 & 9.7 & 2.2 & 1.8 \\
\hline Ostracods & 2.6 & 6.5 & 0.3 & 0.5 \\
\hline Zooplankton & 1.4 & 0.7 & 0.2 & 0.1 \\
\hline Copepods & 1.4 & 0.7 & 0.2 & 0.1 \\
\hline Cladocerans & 0.3 & 0.0 & 0.003 & 0.0 \\
\hline
\end{tabular}




\subsection{Ontogenetic Diet Shifts}

There was no significant variation in the diet of individuals in the size classes I and II $(\alpha=0.88)$, I and III $(\alpha=$ $0.64)$, I and IV $(\alpha=0.60)$, II and III $(\alpha=0.74)$, II and IV $(\alpha=$ $0.68)$ and III and IV $(\alpha=0.95)$. The variation in diet with size of T. zillii was slight in the present study (Figure 2). In general, the importance of macrophytes increased with size whereas the importance of detritus, phytoplankton and insects declined with fish size (Figure 2). In size class $5.0-9.9 \mathrm{~cm}$ TL $T$. zillii fed on macropytes (37.8\%), detritus (36.6\%), phytoplankton (18.8\%) and insects $(9.6 \%)$ of the total volume of food items. The contribution of nematodes (1.2\%) was insignificant. When T. zillii attained 10.0-14.9 TL size class the contribution of macrophytes increased to $47.4 \%$ while the importance of detritus, phytoplankton and insects decreased to $29.5 \%, 14.4 \%$ and $4.6 \%$, of the mean volume in the size class, respectively (Figure 2).

In the size class 15.0-19.9 $\mathrm{cm}$ TL the importance of macrophytes further increased to $71.8 \%$. The importance of the remaining food items, namely, detritus, phytoplankton and insects declined to $12.5 \%, 8.6$ and $4.0 \%$, respectively (Figure 2). When T. zillii attained the size class 20.0-24.9 $\mathrm{cm}$ TL, the volumetric contribution of macrophytes increased to $76.1 \%$. Detritus, phytoplankton and insects declined to $10.9 \%, 7.2 \%$ and $2.6 \%$ of the total volume in the size class, respectively (Figure 2).

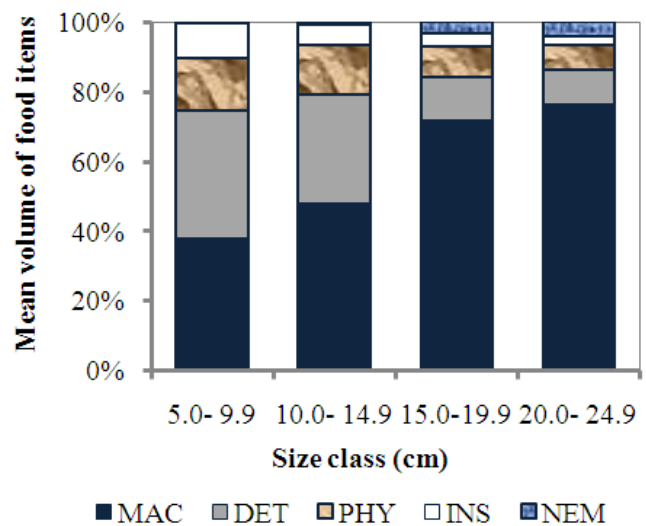

Figure 2. Percent mean volume of food items consumed by different size classes of T. zillii sampled from Lake Ziway (MAC-Macrophytes, PHYPhytoplankton, DET-Detritus, INS-Insects, NEM-Nematodes).

Generally, the importance of macrophytes increased with fish size whereas the importance of detritus, phytoplankton and insects declined with size of fish. The contribution of nematodes was insignificant in all size classes (Figure 2).

\section{Discussion}

Analysis of stomach contents during this study indicated that $T$. zillii fed on a variety of food categories including macrophytes, detritus, phytoplankton, insects, zooplankton, nematodes and ostracods. Various authors studied the feeding habits of $T$. zillii in different parts of African water bodies and reported its herbivorous feeding habits [3, 5-6, 21].

During the present work T. zillii was found to be confined to the littoral habitat. This preference of littoral areas could be due to its herbivorous feeding habits. This is in agreement with the findings of Siddiqui [21] in Lake Naivasha (Kenya) and Markos et al. [10] in Lake Ziway (Ethiopia). Spataru [5] studying T. zillii, in Lake Kinneret (Israel) and Negassa and Padanillay [7] working with the same fish in Lake Ziway (Ethiopia), both reported the importance of macrophytes in the diet of the species. In addition to macrophytes $T$. zillii also consumed other food categories, including phytoplankton, detritus, insects and zooplankton [2-3, 6].

Negassa and Padanillay [7] reported that the importance of food of animal origin such as insects (Diptera and Ephemeroptera), zooplankton mainly Copepoda and Cladocera and fish scales in the diet of T. zillii. Spataru [5] and Negassa and Getahun [2] indicated the importance of phytoplankton consisting of diatoms, blue green algae, green algae and euglenoids in Lake Kinneret (Israel) and Lake Ziway (Ethiopia). Negassa and Padanillay [7] also reported the importance of detritus, nematodes and ostracods in the diet of T. zillii in Lake Ziway. Since the works of Negassa and Getahun [2] and Negassa and Padanillay [7] used only frequency of occurrence of different food items, it was not possible to compare the volumetric importance of the different food categories to the species.

Monthly fluctuation has great effect on the availability and contribution of different food categories. In this study, the most important food categories that constituted the bulk of the food during the dry season were macrophytes, detritus, phytoplankton and insects. Macrophytes were the most important food items both during the dry season $(50.4 \%$ by volume) and the wet season ( $51.4 \%$ by volume). The present study is in agreement with the findings of Adama et al. [22] in Sahelo-Sudanian Rivers (Burkina Faso) and Negassa and Padanillay [7] in Lake Ziway (Ethiopia). The contributions of detritus and insects during the dry season were relatively lower than the wet season. Various authors have reported the lower importance of detritus and insects to the diet of tilapia species such as T. zillii and O. niloticus during dry season [23-25].

According to Njiru et al. [26] the importance of phytoplankton was relatively low during the wet season than the dry season in Lake Victoria (Kenya) in the diet of $O$. niloticus. In the present study, among the phytoplankton groups, diatoms contributed the highest volume during the dry season than the wet season. The reason for the abundance of this food items during the dry season could be autotrophic nature of the phytoplankton using light as their energy input for their growth [5]. During the dry season, the water of Lake Ziway may not be as turbid as in the wet season because during the wet season large quantities of silt is brought into the lake through runoff and tributary rivers such as River Meki and River Katar. The 
silt brought during the wet season increases the turbidity of the lake and reduces algal growth. The importance of minor food categories such as nematodes, ostracods and zooplankton was also relatively high during the dry season in the diet of $T$. zillii in the present study. Legner [27] reported that the importance of zooplankton during dry season in California. Several other investigators also reported the relative importance of nematodes and ostracods during dry season than the wet season in Lake Naivasha (Kenya) [22], Lake Kinneret (Israel) [5], Lake Ziway [2] and in two West African reservoirs, Selingue and Manantai (Mali) [28].

During the wet season, detritus was the most important food item of $T$. zillii in Lake Ziway ( $40.8 \%$ by volume). The source of this food item could be the floods that introduce different plant materials into the Lake and the leaves of plants that fall into the lake from the emergent macrophytes. Negassa and Getahun [2] reported high contribution of plant materials and detritus in the diet of $T$. zillii during the wet season. The same authors reported that these food items are highly dispersed along the surface of the water column at wet period of the year due to floods. In the present study, macrophytes constituted $37.8 \%$ of the total volume in Lake Ziway during the wet season. Tadesse [29] also reported that macrophytes and detritus were the dominant food items during the wet season than the dry season in the diet of $O$. niloticus in Lake Ziway. The present work revealed that the contribution of insects was relatively high in the wet season than the dry season. This is in agreement with the results of Akinuwmi [6] where the availability of insects was more important in the wet season than the dry season.

From the results of the present study, it was evident that T. zillii undergoes slight ontogenetic diet shift during its life cycle. Based on the volumetric contributions of different food items the relative importance of detritus, phytoplankton and insects was high in the stomachs of juveniles (5.0-9.9 cm TL and 10.0-14.9 cm TL), whereas, in the stomachs of adults (15.0-19.9 cm TL and 20.9-24.9 cm TL), macrophytes were the dominant food category. Other investigators have also reported the importance of detritus, phytoplankton, insects and nematodes in the diet of juvenile T. zillii in Lake Naivasha (Kenya) [28], Lake Kennert (Israel) [5] and Lake Ziway (Ethiopia) [2]. The most probable reason why juvenile $T$. zillii feed on these food items could be that these food items are abundant in the littoral part of the lake where weed-bed fauna and decomposing plant materials are found in higher quantities. Juvenile $T$. zillii normally live in this environment in order to protect themselves from the risk of predators [4].

The results of this study also clearly showed that as fish increased in size, the importance of macrophytes increased while the importance of phytoplankton, detritus and insects declined sharply. This is in agreement with the findings of Wanink and Joordens [30] (Lake Victoria), Negassa and Getahun [2] and Negassa and Padanillay [7] in Lake Ziway. Mosaad [31] reported that adult T. zillii ingest benthic invertebrates and insects in Lake Quarn (Egypt). The results of the present study are also in agreement with these findings, but the volumetric contribution of these macro-invertebrates was comparatively low in the present study. Meyer [32] pointed out the change in composition of the diet as the fish grows with an increase in the minimum size of organisms eaten. Akinuwmi [6] reported that adult $T$. zillii mainly feed on macrophytes in Ondo State University Fish Farm, Nigeria. Various workers [5, 23, 31] in Lake Kinneret (Israel), Lake Victoria (Kenya) and Sahelo-Sudanian Reservoirs (Burkina Faso), respectively pointed out the significant contributions of nematodes in the diet of adult $T$. zillii. In contrast to the above findings, nematodes played insignificant role in the diet of T. zillii in Lake Ziway.

\section{Conclusion}

The results of the present study have clearly indicated that the most important food categories of T. zillii in Lake Ziway were macrophytes, phytoplankton, detritus and insects. Food of minor importance were nematodes, ostracods and zooplankton. During the dry season, macrophytes and phytoplankton were the most important food categories whereas their contributions declined sharply during the wet season. On the other hand, detritus was the most important food category during the wet season but its contribution declined during the dry season. Ontogenetic diet shift was slight in the present study. The relative importance of detritus, phytoplankton and insects was high in the diet of juveniles. As the size of fish increased the importance of macrophytes increased whereas the importance of phytoplankton, detritus and insects declined sharply.

\section{Acknowledgements}

We thank fishermen Fikre Dolie and Birhanu Bante for their assistance during sample collection. The Biology Department of Hawassa University deserves special thanks for providing laboratory materials and other facilities during the study period. We are grateful to Mrs. Yirgashewa Bekele who assisted us during stomach content analysis. Ministry of Education, Addis Ababa, Ethiopia, provided financial support for the second author.

\section{References}

[1] El- Shazly A. 1993. Biological studies on four cichlid fishes (Tilapia nilotica, Tilapia galilae, Tilapia zillii, Tilapia aurea). MSc Thesis, Zagazig University, Egypt.

[2] Negassa A. and Getahun A. 2004. Breeding season, length-weight relationship and condition factor of introduced fish, Tilapia zillii (Gervais, 1848) (Pisces: Cichlidae) in Lake Ziway, Ethiopia. SINET: Ethiop. J. Sci. 26(2): 115-122. 
[3] Kariman A.S.H. and Nadhan G. 2009. Some observations on fisheries biology of Tilapia zillii (Gervais, 1848) and Solea vulgaris (Quensel, 1806) in Lake Qarun, Egypt. World Fish Mari. Sci. 1(1): 20-28.

[4] Mehanna S.F. 2004. Population dynamics of two cichlids, Oreochromis aureus and Tilapia zillii, from Wadi El-Raiyan Lakes. Egypt. Agri. Marine Sci. 9(1):9-16.

[5] Spataru P. 1978. Food and feeding habits of Tilapia zillii (Gervais, 1848) (Cichlidae) in Lake Kinneret (Israel). Aquaculture 14(4): 327-338.

[6] Akinuwmi F.O. 2003. Food and feeding habits of Tilapia zillii (Pisces: Chichlidae) in Ondo State University Fish Farm. Proceeding of the $16^{\text {th }}$ Annual Conference of the Fisheries Society of Nigeria (FISON), Department of Environmental Biology and Fisheries (Nigeria).

[7] Negassa A. and Padanillay C. 2008. Abundance, food habits, and breeding season of exotic Tilapia zillii and native Oreochromis niloticus fish species in Lake Ziway, Ethiopia, Mj. Int. J. Sci. Tech. 2: 345-359.

[8] Adeyemi S.O., Bankole N.O., Adikwu I.A. and Akombu P.M. 2009. Food and feeding habits of some commercially important fish species in Gbedikere Lake, Bossa, Kogi State, Nigeria. Int. J. Lakes and Rivers 2(1): 31-36.

[9] Mohamoud F.W., Amin M.A., Elboray F.K., Ramadan M.A. and Halfawy O.K. 2011. Reproductive biology and some observation on the age, growth, and management of Tilapia zillii (Gervais: 1848) from Lake Timsah, Egypt. Int. J. Fish. Aquac. 3(2): 16-26.

[10] Markos T., Reidar B. and Bjørn O.R. 2011. Mercury concentrations are low in commercial fish species of Lake Ziway, Ethiopia, but stable isotope data indicated biomagnifications. Ecotox. Environ. Safety 74: 953-959.

[11] Makin M.J., Kingham T.J., Waddans A.E., Birchall C.H. and Tamene T. 1975. Development prospects in the southern rift valley, Ethiopia. Land Resources Division, Ministry of Overseas Development 142: 324-567.

[12] Ayenew T. 1998. The hydro biological system of the Lake District basin, central main Ethiopian rift valley, International Institute of Aerospace Survey and Earth Sciences. PhD Thesis, Earth Sciences, the Netherlands.

[13] Lemma A. 2005. Site action plan for conservation and sustainable use of the Lake Ziway biodiversity, Rift Valley Lakes Project, Institute of Biodiversity, Addis Ababa.

[14] Admassu D. and Ahlgren I. 2000. Growth of juvenile tilapia, Oreochromis niloticus L. from Lakes Ziway, Langeno and Chamo (Ethiopian rift valley) based on otolith micro-increment analysis. Ecol. Freshwat. Fish 9(3): 127-137.

[15] Lake Fisheries Development Project (LFDP) (1998) Fisheries development in Ethiopia: which way now? Project. News. Bulletin.11 no. 1. Lake Fisheries Development Project, Addis Ababa, Ethiopia.

[16] Hyslop E.J. 1980. Stomach contents analysis-a review of methods and their application. J. Fish Biol. 17: 411-429.
[17] Wallace R.K. 1981. An assessment of Diet-Overlap Indexes. Trans. Am. Fish. Soc. 110: 72-76.

[18] Sokal R.R. and Rohlf F.J. 1995. Biometry: The principles and practices of statistics in biological research 3rd ed. New York, Freeman and Company, pp. 859.

[19] Schoener T.W. 1970. Non-synchronous spatial overlap of lizards in patchy habitats. Ecology 51: 408-418.

[20] Mathur D. 1977. Food habits and competitive relationships of Bandfin shiner in Halawakee Creek, Alabama. Am. Midland Natura. 97: 89-100.

[21] Siddiqui A.Q. 1977. Reproductive biology, length-weight and relative condition of Tilapia leucostica (Trewaeva) in Lake Naivasha, Kenya. J. Fish Biol. 10: 351-260.

[22] Adama O., Wendengouing G., Allassane O., Germain G. and Brnerd H. 2008. Seasonal diet shift of the most important fish species in a Sahelo-Sudanian Reservoirs (Burkina Faso). J. Fish. Aquat. Sci. 3(4): 240-251.

[23] Brown J. A. 1986. The development of feeding behavior in the Cichlidae. J. Fish Biol. 29: 17-178.

[24] Layman C.A. and Silliman B.R. 2002. Preliminary survey and diet analysis of juvenile fishes of an estuarine creek on Andros Island, Bahamas. Bull Mar. Sci. 70(1): 199-210.

[25] Layman C.A., Quattrochi J.P., Peyer C.M. and Allgeier J.E. 2007. Niche width collapse in a resilient top predator following ecosystem fragmentation. Ecol. Lett. 10(10): 937-944.

[26] Njiru M., Okeyo-Owuor J.B., Muchiri M. and Cowx I.G. 2004. Shifts in the food of Nile tilapia, Oreochromis niloticus (L.) in Lake Victoria, Kenya. Afr. J. Ecol. 42: 163-170.

[27] Legner E.F. 1978. Mass culture of Tilapia zillii (Cichlidae) in pond ecosystems. Entomopora 23: 51-55.

[28] Perga M.E., Arfi R. and Gerdeaux F. 2005. Seasonal variations in fish $\mathrm{d} 13 \mathrm{C}$ and $\mathrm{d} 15 \mathrm{~N}$ in two West African reservoirs, Selingue and Manantali (Mali): modification of trophic links in relation to water levels. Isotoes. Environ. Health Stud. 41(2): 1-15.

[29] Tadesse Z. 1988. Studies on some aspects of the biology of Oreochromis niloticus L. (Pisces: Cichlidae) in Lake Ziway, Ethiopia. MSc Thesis, Addis Ababa University, Addis Ababa.

[30] Wanink H. and Joordens C.A. 2003. Dietary shifts in Brycinus sadleri (Pisces: Characidae) from Southern Lake Victoria. Inst. Evolut. Ecol. Sci. 12: 230-350.

[31] Mosaad M.N.M. 1990. Biological studies on five fish species from Lake Qarun, Egypt: length-weight relationship and condition factor. Proc. Zool. Soc. Egypt 21: 331-344.

[32] Meyer D.E. 2002. Technology for successful small-scale tilapia culture (CRSP Research Report 02- 179). CRSP (Aquaculture Collaborative Research Support Program). Tilapia Sessions 2: 97-106. 